\title{
Plaque morphology (the PLAC Scale) on CT angiography: predicting long-term anatomical success of primary carotid stenting
}

\author{
David M. Pelz, MD, FRCPC, Stephen P. Lownie, MD, FRCSC, Donald H. Lee, MD, FRCPC, \\ and Melfort R. Boulton, MD, FRCSC
} Departments of Medical Imaging and Clinical Neurological Sciences, Schulich School of Medicine and Dentistry,
Western University, London, Ontario, Canada

\begin{abstract}
OBJECT Carotid angioplasty and stenting has emerged as an alternative to carotid endarterectomy for the treatment of atherosclerotic carotid stenosis. Primary carotid stenting, performed using self-expanding stents alone without deliberate use of embolic protection devices and balloon angioplasty, has been shown to be effective and faster, cheaper, and potentially safer than conventional techniques. However, the long-term morphological results of this technique have not been established. The aim of this study was to determine whether preprocedural carotid plaque imaging at the site of maximal stenosis by using CT angiography (CTA) could predict the long-term morphological outcome of primary carotid stenting.

METHODS One hundred eighty-one patients were treated over an 11-year period. Preprocedural CTA was performed in 102 of these. A morphological scale (the Predicting Long-term outcome with Angioplasty of the Carotid artery [PLAC] Scale), with grades from 0 to 4 and $A$ or $B$, was used to evaluate the circumferential degree of plaque calcification, and the presence or absence of soft plaque. All patients were followed using duplex carotid ultrasound and plain radiographs. Satisfactory morphological outcome was defined as a peak systolic velocity $<120 \mathrm{~cm} / \mathrm{s}$ and internal carotid artery/common carotid artery ratio $<1.4$.
\end{abstract}

RESULTS The average follow-up duration was 29.7 months (median 24.5 months, range $0.3-87$ months). Univariate logistic regression demonstrated that a low calcification grade $(p<0.001)$, less thick calcification $(p<0.001)$, and moderate amounts of soft plaque $(p<0.001)$ are factors that are highly associated with good long-term outcome. Multivariate analyses confirmed that these factors are independent of each other in predicting outcome.

CONCLUSIONS The long-term morphological outcome of primary carotid stenting was predicted with considerable accuracy by using a straightforward CTA carotid plaque grading scale.

http://thejns.org/doi/abs/10.3171/2014.9.JNS14811

KEY WORDS carotid stenting; carotid stenosis; CT angiography; plaque morphology; vascular disorders

$\mathrm{C}$ AROTID angioplasty and stenting (CAS) has evolved into an alternative to carotid endarterectomy (CEA) for the treatment of atherosclerotic carotid stenosis, particularly since the publication of the Carotid Revascularization Endarterectomy versus Stent Trial (CREST) in $2010 .{ }^{4}$ In the CREST, as in most other randomized controlled trials and large case series, the standard technical protocols include the use of embolic protection devices (EPDs), self-expanding stents (SESs), and balloons preand postdilation. It has, however, been shown that EPDs do not catch all debris generated by balloons and that these expensive devices may cause complications themselves. ${ }^{10}$ Every pass of a device through an atherosclerotic stenosis generates distal emboli. ${ }^{2,31}$ Balloon angioplasty, both before and after stent insertion, releases significant amounts of embolic debris ${ }^{20,24,26,28,33}$ and often results in significant hemodynamic instability, defined as bradycardia $(<60$ beats/min) and hypotension (systolic blood pressure $<90$ $\mathrm{mm} \mathrm{Hg}){ }^{27}$ Some major centers now rarely perform prestent balloon angioplasty, deliberately undersize poststent

ABBREVIATIONS CAS = carotid angioplasty and stenting; CEA = carotid endarterectomy CREST = Carotid Revascularization Endarterectomy versus Stent Trial; $C$ TA = CT angiography; EPD = embolic protection device; NASCET = North American Symptomatic Carotid Endarterectomy Trial; PCS = primary carotid stenting; PLAC = Predicting Long-term outcome with Angioplasty of the Carotid artery; PSV = peak systolic velocity; SES = self-expanding stent.

SUBMITTED April 16, 2014. ACCEPTED September 30, 2014.

INCLUDE WHEN CITING Published online March 27, 2015; DOI: 10.3171/2014.9.JNS14811.

DISCLOSURE The authors report no conflict of interest concerning the materials or methods used in this study or the findings specified in this paper. 
angioplasty balloons, or completely omit poststent angioplasty to decrease the potential for embolic events and hemodynamic depression. ${ }^{11,23,27}$

In an attempt to lessen the technical complexity, risks, and cost of CAS, several groups have shown that the procedure can be performed safely in the majority of cases without the use of EPDs and balloon angioplasty.,3,6,17,18 Our group has shown that primary carotid stenting (PCS) performed using SESs alone can be successful in treating more than $80 \%$ of patients with severe, symptomatic carotid stenosis who are ineligible for endarterectomy. ${ }^{6,18}$ Potential drawbacks of this balloonless approach include inadequate intraprocedural arterial expansion and early restenosis.

During our review of case material, it became apparent that the morphological appearance of carotid plaque on CT angiography (CTA) was an important predictor of SES expansion and the angiographic success of PCS. It could also help to determine whether the use of balloons and EPDs would be necessary to achieve a satisfactory angiographic result. We found that the amounts of calcification and "soft" or uncalcified plaque at the site of maximal stenosis are important predictors of whether the SES alone can satisfactorily dilate the stenosis in both the short and long term. We therefore undertook a detailed analysis of the CTA morphology of the carotid plaques in our patients undergoing CAS to develop a rating scale (which we have labeled the "PLAC Scale": Predicting Long-term outcome with Angioplasty of the Carotid artery) to both predict the long-term imaging success of CAS and to help guide the subsequent technical performance of the procedure.

\section{Methods}

At our center, CAS is reserved for patients with severe (> 70\% by North American Symptomatic Carotid Endarterectomy Trial [NASCET] criteria), symptomatic stenosis who are ineligible for endarterectomy due to medical comorbidities, prior neck radiation therapy, or prior CEA with restenosis. Our current practice is to perform CTA on all potential CAS candidates, although earlier in our experience we treated patients on the basis of duplex carotid ultrasound and MR angiography imaging, without a preoperative CTA. We treated 181 patients between March 2000 and February 2011. Our technical and imaging follow-up protocols for CAS have been published previously. ${ }^{6,18}$

We use an $8 \times 40-\mathrm{mm}$ SES to ensure good plaque coverage and maximal chronic outward force on the stenotic area. Our preference is to avoid the use of EPDs and balloons whenever the plaque morphology appears favorable on preoperative CTA. A calcification scale based on CTA axial source images at the site of maximal stenosis, modified from existing scales of intracranial carotid calcification, ${ }^{1}$ is used to assess the degree of plaque calcification (Table 1). This 5-point scale includes the following grades: Grade 0, indicating absence of calcification; Grade 1, indicating involvement of $<25 \%$ of vessel circumference; Grade 2, indicating $25 \%-50 \%$ of vessel circumference; Grade 3, indicating $50 \%-75 \%$ of vessel circumference; and Grade 4, indicating complete circumferential plaque calcification (Fig. 1). Thickness and continuity of calcifi-
TABLE 1. The PLAC Scale

\begin{tabular}{cccccc}
\hline & \multicolumn{5}{c}{ Calcification Grade (\% vessel circumference affected) } \\
\cline { 2 - 6 } Moderate & & 1 & 2 & 3 & 4 \\
Soft Plaque & $0(0 \%)$ & $(0-25 \%)$ & $(25-50 \%)$ & $(50-75 \%)$ & $(75-100 \%)$ \\
\hline Present (A) & A0 & A1 & A2 & A3 & A4 \\
\hline Absent (B) & B0 & B1 & B2 & B3 & B4 \\
\hline
\end{tabular}

cation are also assessed. "Soft" plaque is defined as noncalcified plaque on CTA source images. The amount of soft plaque is characterized as either moderate $(\geq 2 \mathrm{~mm})$ or minimal $(<2 \mathrm{~mm})$. The presence (Grade A) or absence (Grade B) of moderate amounts of soft plaque at the level of maximal stenosis is determined (Fig. 2). The PLAC score is the combination of soft plaque status and calcification grade (i.e., A1).

Prospective and retrospective grading was performed by 2 of the authors (D.M.P. and S.P.L.) on an individual basis, with discrepancies resolved by consensus. Both authors were involved in some of the interventions.

Duplex carotid ultrasound examinations, including peak systolic velocity (PSV) and internal carotid artery/common carotid artery velocity ratio measurements, are performed prior to and immediately following the procedure. These are subsequently repeated at 1 week, 4 months, 1 year, and annually thereafter. Long-term PSV outcome of $<120$ $\mathrm{cm} / \mathrm{s}$ (normal or $<50 \%$ residual stenosis by NASCET criteria) and internal carotid artery/common carotid artery ratio $<1.4$ are defined as acceptable. A successful outcome is defined as an acceptable long-term PSV and absence of recurrent ipsilateral neurological symptoms. Restenosis is defined as PSV $>230 \mathrm{~cm} / \mathrm{s}\left(>70 \%\right.$ by NASCET criteria $\left.^{12}\right)$.

Associations between treatment and prognostic factors and stroke, restenosis, and morphological outcome were evaluated using unpaired t-tests for continuous factors and either chi-square tests or, where appropriate, Fisher's exact test for categorical variables. Univariate analysis was followed by multivariate analysis of significant variables. Probability values less than 0.05 were considered to be statistically significant. Statistical software (SAS version 9.3) was used to analyze the data. Analysis was performed by an independent biostatistician (L. Stitt).

\section{Results}

One hundred eighty-one consecutive patients who underwent CAS were available for analysis. Of these, CTA was performed prior to CAS in 102 patients and formed the basis for our study of plaque morphology. The mean age was 72 years (range 48-91 years). There were 87 patients $(85 \%)$ who underwent PCS, whereas 15 patients (15\%) underwent CAS with balloons. The latter patients were either enrolled in the CREST trial or had an unsatisfactory intraprocedural angiographic result with PCS. An EPD was used in 19 patients (19\%).

All patients presented with either ipsilateral stroke or transient ischemic attacks. There were 3 who had received prior neck radiation and 9 who had undergone prior ipsilateral CEA. The remainder had multiple medical comorbidities precluding CEA, including coronary artery and 



FIG. 1. Axial source images from CTA of carotid bifurcation stenosis. Examples of calcium grade. A: Grade 0 on the left (arrow). B: Grade 1 on the right (arrow). C: Grade 2 on the left (arrow). D: Grade 3 on the right (arrow). E: Grade 4 on the right (arrow).

chronic respiratory disease, diabetes, hyperlipidemia, and combined hypertension and diabetes.

The mean preprocedural PSV in these patients was 405 $\mathrm{cm} / \mathrm{s}$. The average diameter stenosis was $1.3 \mathrm{~mm}$, and the average NASCET stenosis was $78 \%$.

For the PLAC score, intraclass correlation coefficients and weighted kappa coefficients were used to determine the intraobserver reliabilities in 25 cases, assuming random times of assessments. For calcium grade the intraclass correlation coefficient was $83 \%$ (95\% CI 0.65-0.92), indicating very good reliability. The kappa coefficient was 0.64 (95\% CI 0.46-0.82), indicating good reliability. For calcium thickness, and for the presence or absence of moderate soft plaque, kappa coefficients were 0.40 and 0.61 , respectively, indicating fair to good reliability.

The calcification grade was distributed as follows: $17 \%$ were Grade $0 ; 15 \%$ were Grade 1; $19 \%$ were Grade 2; $33 \%$ were Grade 3; and $16 \%$ were Grade 4 . Approximately half of the plaques were therefore Grade 3 or 4 . Thirty percent had thick plaque calcification. Soft plaque in any amount was observed in $86 \%$, while in $74 \%$ soft plaque was present to a moderate degree.

Overall incidence of any periprocedural 30-day stroke or death was $5.9 \%$. The 30 -day major stroke or death rate was $2 \%$. In terms of plaque characteristics and incidence of stroke, there was no relationship to plaque calcification, although there was a trend toward an association with Grade 2, 3, or 4 versus Grade 0 or 1 plaques $(p=0.076)$. There was no association with the severity of stenosis $(\mathrm{p}=$ $0.885)$ or the use of balloons ( $p=0.470$ ).

The average ultrasound follow-up was 29.7 months (range 0.3-87 months). Results showed PSV under 200 $\mathrm{cm} / \mathrm{s}$ in 80 of 102 patients (78\%). Of these, $52 \%$ were less than $110 \mathrm{~cm} / \mathrm{s}, 5 \%$ were between 110 and $120 \mathrm{~cm} / \mathrm{s}$, and $26 \%$ were between 120 and $199 \mathrm{~cm} / \mathrm{s}$.

Significantly fewer patients with Grade 3 or 4 calcification attained a PSV $<120 \mathrm{~cm} / \mathrm{s}$ versus those with Grade 0,1 , or 2 plaques ( 19 of 50 [38\%] vs 39 of 52 [75\%], p < 0.001 , Table 2). The same was true of thick calcification: only $25 \%$ (8 of 31) of thickly calcified plaques improved to PSV $<120 \mathrm{~cm} / \mathrm{s}$ versus $70 \%$ (50 of 71) of thinly calcified ones $(\mathrm{p}<0.001)$. With respect to soft plaque, the presence of any soft plaque, but particularly to a moderate or high degree, was significantly greater in patients who attained a $\mathrm{PSV}<120 \mathrm{~cm} / \mathrm{s}$ than in those who did not (50 of 74 [68\%] vs 8 of 28 [29\%], p < 0.001). Multivariate logistic regression confirmed calcium grade, calcium thickness, and the presence of moderate to large amounts of soft plaque as independent significant variables. However, neither the presence of soft plaque (minimal or moderate in amount), nor the degree of continuity of the calcification surrounding the lumen entered the regression equation. 

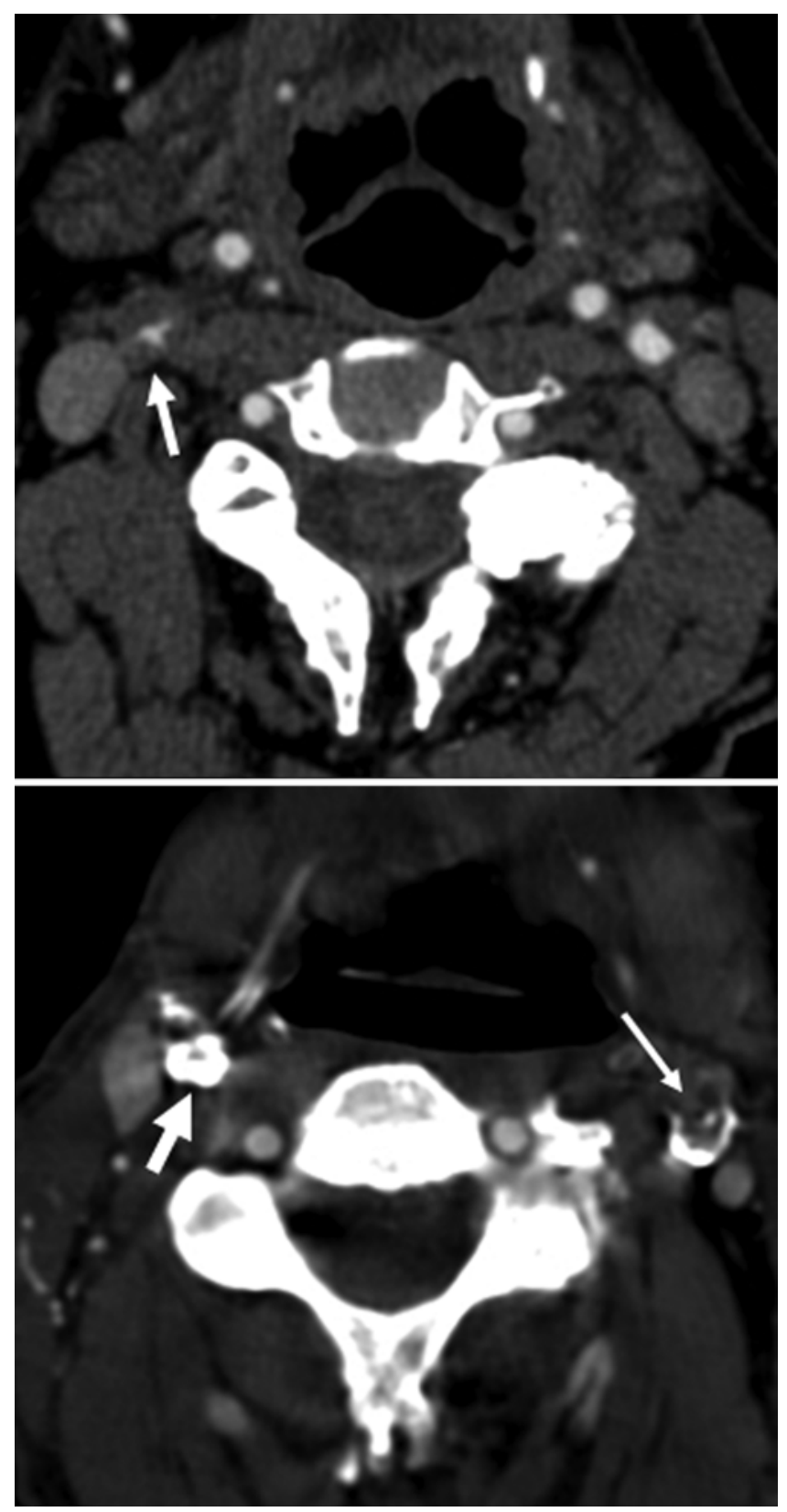

FIG. 2. Axial source images from CTA of carotid bifurcation stenosis. Examples of soft plaque, either Grade A (present) or Grade B (absent). Upper: Grade A on the right (arrow). Lower: Grade B on the right (thick arrow), Grade A on the left (thin arrow).

When the 15 patients who underwent balloon angioplasty were excluded from the analysis, the results were the same as in the entire CAS cohort. Calcification Grade 3 or $4(p=0.003)$ and calcification thickness $(p<0.001)$ were both significant predictors of unsatisfactory morphological outcome. When the patients undergoing CAS for postradiation or postendarterectomy restenosis (12 patients, none of whom required balloon angioplasty) were also excluded, only calcification thickness $(\mathrm{p}=0.002)$ was a predictor of unsatisfactory outcome.

The restenosis rate at 2 years was $11.8 \%$ (Table 3 ). Plaque calcification was found to have an association: 10
TABLE 2. Factors analyzed for relationship with outcome in 102 patients with primary CAS

\begin{tabular}{lccc}
\hline \multirow{2}{*}{ Characteristic } & \multicolumn{2}{c}{ Outcome: PSV <120 cm/s } & \\
\cline { 2 - 3 } \multicolumn{1}{c}{ No } & Yes & p Value \\
\hline No. of patients & 44 & 58 & \\
\hline Stent used alone & $36(81.8 \%)$ & $51(87.9 \%)$ & 0.388 \\
\hline Balloon used prestent & $5(11.4 \%)$ & $5(8.6 \%)$ & 0.742 \\
\hline Balloon used poststent & $4(9.1 \%)$ & $2(3.5 \%)$ & 0.397 \\
\hline Mean stenosis in mm & 1.20 & 1.38 & $0.323^{*}$ \\
\hline Calcification Grade 3 or 4 & $31(70.5 \%)$ & $19(32.8 \%)$ & $<0.001$ \\
\hline Thick calcification & $23(52.3 \%)$ & $8(13.8 \%)$ & $<0.001$ \\
\hline $\begin{array}{l}\text { Moderate amount of soft } \\
\text { plaque }\end{array}$ & $24(54.5 \%)$ & $50(86.2 \%)$ & $<0.001$ \\
\hline
\end{tabular}

* Log-transformed to improve normality.

of $50(20 \%)$ of highly calcified Grade 3 or 4 plaques developed restenosis, whereas only $4 \%$ of less calcified or noncalcified plaques restenosed.

The predictive value of individual PLAC scores for satisfactory morphological outcome of PSV $<120 \mathrm{~cm} / \mathrm{s}$ is shown in Table 4 . The presence of soft plaque and lower grades of calcification were positively predictive of a satisfactory morphological outcome.

\section{Discussion}

Diagnostic evaluation of cervical carotid atherosclerosis has evolved from catheter-based angiography to less invasive modalities such as ultrasound, CT, and MRI. Not only can stenosis be measured, but carotid plaque can also be characterized. Plaque morphology on CTA has been correlated with histopathological findings in postendarterectomy surgical specimens to identify "vulnerable" or unstable plaque, which is most likely to cause symptoms. ${ }^{19,25,32}$ Only 1 paper classified calcification into definite shapes and thicknesses and posited a relationship to expansion of intravascular balloons and stents. ${ }^{22}$ Recent investigations have used MRI to more accurately detect lipid content, plaque hemorrhage, necrosis, ulceration, and thin fibrous cap to identify unstable plaque. ${ }^{14}$ The CTA modality with modern, multislice scanners is excellent for localization and quantification of calcification, ${ }^{21}$ and the relationship to internal architecture, ulceration, and prediction of "vulnerability" is becoming clear. ${ }^{13,29,30} \mathrm{Al}$ though the CT calcification grade is known to predict the expansion of coronary stents ${ }^{15}$ and has been suggested to be a relative contraindication to $\mathrm{CAS},{ }^{8,16}$ few investigators use plaque morphology to help guide the choice of treatment ${ }^{19}$ or to predict the immediate or long-term morphological success of CAS procedures.

This study has shown that high-grade plaque calcification (Grade 3 or 4 ) is a very significant factor determining the long-term morphological outcome of CAS $(\mathrm{p}<$ $0.001)$ when either PCS or standard balloon techniques are used. The presence of moderate amounts of soft plaque $(\mathrm{p}<0.001)$ and the presence of thick calcification $(\mathrm{p}<0.001)$ are also significant factors. High-grade calci- 
TABLE 3. Factors analyzed for relationship to restenosis in 102 patients with primary CAS

\begin{tabular}{lccc}
\hline \multirow{2}{*}{ Characteristic } & \multicolumn{2}{c}{ Restenosis: PSV >230 cm/s } & \\
\cline { 2 - 3 } \multicolumn{1}{c}{ No } & Yes & p Value \\
\hline No. of patients & 90 & 12 & \\
\hline Preop PSV in cm/s & 402 & 430 & 0.602 \\
\hline Mean stenosis in mm & 1.31 & 1.22 & $0.809^{*}$ \\
\hline Stent used alone & $86.7 \%$ & $75 \%$ & 0.378 \\
\hline Balloon used prestent & $8.9 \%$ & $16.7 \%$ & 0.334 \\
\hline Balloon used poststent & $5.6 \%$ & $8.3 \%$ & 0.542 \\
\hline Calcification Grade 3 or 4 & $44.4 \%$ & $83.3 \%$ & 0.011 \\
\hline $\begin{array}{c}\text { Moderate amount of soft } \\
\text { plaque }\end{array}$ & $76.1 \%$ & $58.3 \%$ & 0.290 \\
\hline
\end{tabular}

* Log-transformed to improve normality.

fication is a significant predictor of subsequent restenosis $(\mathrm{p}=0.011)$.

Primary carotid stenting has in our experience proven to be a safe, efficient, and less complicated method to treat the majority of symptomatic patients with severe carotid stenosis. ${ }^{6,18}$ This procedure is particularly effective for the treatment of postendarterectomy restenosis, and, due to the avoidance of balloon angioplasty, it results in less hemodynamic instability. ${ }^{5}$ Although progressive SES expansion can be seen up to 6 months postprocedure, ${ }^{9}$ our results show that PCS is less likely to give a satisfactory longterm result in the presence of significant plaque calcification and the absence of soft plaque (PLAC score of B3 or 4). We believe that abundant calcification and the absence of soft, compressible plaque opposes the outward force of the SES and prevents satisfactory short- and long-term stent expansion. ${ }^{34}$ In our experience, this phenomenon was also observed when balloon angioplasty was used.

Our current practice is to assess the degree of calcification and soft plaque status on axial CTA source images in all patients who may undergo CAS. If the calcification grade is low (0-2) and soft plaque is present (Grade A; i.e., a PLAC score of A0, A1, or A2), we will proceed with the intent to perform PCS. If the calcification grade is high (3-4) and soft plaque is absent (Grade B; i.e., a PLAC score of B3 or B4), we will perform CAS with the anticipated use of balloon angioplasty and EPDs, or reassess patient eligibility for endarterectomy, depending on patient age and medical comorbidities. An A1 plaque would therefore probably be excellent for PCS, whereas in a patient with B4 plaque, balloon angioplasty would probably be necessary before stent placement to achieve a satisfactory long-term anatomical result.

There are several limitations to our study. The sample size is relatively small, with very few patients undergoing balloon angioplasty at our center compared with highvolume centers. There were very few patients with certain categories of carotid plaque (i.e., B0, B1, and B2; Table 4). It is possible that a small minority of plaques with little calcium and soft plaque may also be unsuitable for PCS. Also, this is a retrospective review and observer bias could have affected grading scores.
TABLE 4. Predictive value of PLAC Scale for PSV $<120 \mathrm{~cm} / \mathrm{s}$ vs $\geq$ $120 \mathrm{~cm} / \mathrm{s}$ in 102 patients with primary CAS*

\begin{tabular}{ccc}
\hline PLAC Scale & PSV $<120 \mathrm{~cm} / \mathrm{s}$ & PSV $\geq 120 \mathrm{~cm} / \mathrm{s}$ \\
\hline A0 & $14(93 \%)$ & $1(7 \%)$ \\
\hline B0 & $1(50 \%)$ & $1(50 \%)$ \\
\hline A1 & $10(67 \%)$ & $5(33 \%)$ \\
\hline B1 & $0(0 \%)$ & $0(0 \%)$ \\
\hline A2 & $14(70 \%)$ & $6(30 \%)$ \\
\hline B2 & $0(0 \%)$ & $0(0 \%)$ \\
\hline A3 & $14(48 \%)$ & $15(52 \%)$ \\
\hline B3 & $1(20 \%)$ & $4(80 \%)$ \\
\hline A4 & $3(33 \%)$ & $6(66 \%)$ \\
\hline B4 & $1(14 \%)$ & $6(86 \%)$ \\
\hline Total no. of patients & 58 & 44 \\
\hline Composite A3 \& A4 & $17(45 \%)$ & $21(55 \%)$ \\
\hline Composite B3 \& B4 & $2(17 \%)$ & $10(83 \%)$ \\
\hline
\end{tabular}

* Except for the total patients, values are expressed as the frequency (\%).

\section{Conclusions}

Long-term morphological outcome of PCS may be predicted with considerable accuracy by using the PLAC Scale, a simple assessment tool involving calcium grading and the observation of soft plaque on diagnostic, preprocedural CTA imaging. Use of this scale can also help to determine whether PCS is a feasible alternative to traditional CAS techniques in which EPDs and balloon angioplasty are used.

\section{Acknowledgments}

We acknowledge the following colleagues: Drs. Irene Gulka, Andrew Leung, Paul Kalapos, and Miguel Bussiere for clinical contributions; L.W. Stitt for statistical analysis; and Cathy Carlisle for administrative assistance.

\section{References}

1. Ahn SS, Nam HS, Heo JH, Kim YD, Lee SK, Han K, et al: Quantification of intracranial internal carotid artery calcification on brain unenhanced CT: evaluation of its feasibility and assessment of the reliability of visual grading scales. Eur Radiol 23:20-27, 2013

2. Almekhlafi MA, Demchuk AM, Mishra S, Bal S, Menon BK, Wiebe S, et al: Malignant emboli on transcranial Doppler during carotid stenting predict postprocedure diffusionweighted imaging lesions. Stroke 44:1317-1322, 2013

3. Baldi S, Zander T, Rabellino M, Gonzalez G, Maynar M: Carotid artery stenting without angioplasty and cerebral protection: a single center experience with up to 7 years' follow-up. AJNR Am J Neuroradiol 32:759-763, 2011

4. Brott TG, Hobson RW II, Howard G, Roubin GS, Clark WM, Brooks W, et al: Stenting versus endarterectomy for treatment of carotid-artery stenosis. N Engl J Med 363:11-23, 2010

5. Bussière M, Lownie SP, Lee D, Gulka I, Leung A, Pelz DM: Hemodynamic instability during carotid artery stenting: the relative contribution of stent deployment versus balloon dilation. J Neurosurg 110:905-912, 2009

6. Bussière M, Pelz DM, Kalapos P, Lee D, Gulka I, Leung A, et al: Results using a self-expanding stent alone in the treat- 
ment of severe symptomatic carotid bifurcation stenosis. J Neurosurg 109:454-460, 2008

7. Bussière M, Pelz DM, Lownie SP: Primary stenting for recurrent stenosis following carotid endarterectomy. Can J Neurol Sci 36:332-335, 2009

8. Choi HM, Hobson RW, Goldstein J, Chakhtoura E, Lal BK, Haser PB, et al: Technical challenges in a program of carotid artery stenting. J Vasc Surg 40:746-751, 2004

9. Clark DJ, Lessio S, O'Donoghue M, Tsalamandris C, Schainfeld R, Rosenfield K: Mechanisms and predictors of carotid artery stent restenosis: a serial intravascular ultrasound study. J Am Coll Cardiol 47:2390-2396, 2006

10. Cloft HJ: Distal protection: maybe less than you think. AJNR Am J Neuroradiol 29:407-408, 2008

11. Dumont TM, Wach MM, Mokin M, Sorkin GC, Snyder KV, Hopkins LN, et al: Perioperative complications after carotid artery stenting: a contemporary experience from the University at Buffalo neuroendovascular surgery team. Neurosurgery 73:689-694, 2013

12. Grant EG, Benson CB, Moneta GL, Alexandrov AV, Baker JD, Bluth EI, et al: Carotid artery stenosis: gray-scale and Doppler US diagnosis-Society of Radiologists in Ultrasound Consensus Conference. Radiology 229:340-346, 2003

13. Gupta A, Baradaran H, Kamel H, Pandya A, Mangla A, Dunning A, et al: Evaluation of computed tomography angiography plaque thickness measurements in high-grade carotid artery stenosis. Stroke 45:740-745, 2014

14. Gupta A, Baradaran H, Schweitzer AD, Kamel H, Pandya A, Delgado D, et al: Carotid plaque MRI and stroke risk: a systematic review and meta-analysis. Stroke 44:3071-3077, 2013

15. Henneke KH, Regar E, König A, Werner F, Klauss V, Metz $\mathrm{J}$, et al: Impact of target lesion calcification on coronary stent expansion after rotational atherectomy. Am Heart J 137:9399, 1999

16. Itami H, Tokunaga K, Okuma Y, Hishikawa T, Sugiu K, Ida $\mathrm{K}$, et al: Novel 3D-CT evaluation of carotid stent volume: greater chronological expansion of stents in patients with vulnerable plaques. Neuroradiology 55:1153-1160, 2013

17. Leonardi M, Dall'olio M, Raffi L, Cenni P, Simonetti L, Marasco R, et al: Carotid stenting without angioplasty and without protection: the advantages of a less invasive procedure. Interv Neuroradiol 14:153-163, 2008

18. Lownie SP, Pelz DM, Lee DH, Men S, Gulka I, Kalapos P: Efficacy of treatment of severe carotid bifurcation stenosis by using self-expanding stents without deliberate use of angioplasty balloons. AJNR Am J Neuroradiol 26:1241-1248, 2005

19. Maldonado TS: What are current preprocedure imaging requirements for carotid artery stenting and carotid endarterectomy: have magnetic resonance angiography and computed tomographic angiography made a difference? Semin Vasc Surg 20:205-215, 2007

20. Manninen HI, Rasanen HT, Vanninen RI, Vainio P, Hippeläinen M, Kosma VM: Stent placement versus percutaneous transluminal angioplasty of human carotid arteries in cadavers in situ: distal embolization and findings at intravascular US, MR imaging, and histopathologic analysis. Radiology 212:483-492, 1999

21. Nandalur KR, Hardie AD, Raghavan P, Schipper MJ, Baskurt E, Kramer CM: Composition of the stable carotid plaque: insights from a multidetector computed tomography study of plaque volume. Stroke 38:935-940, 2007

22. Niwa Y, Katano H, Yamada K: Calcification in carotid ath- eromatous plaque: delineation by 3D-CT angiography, compared with pathological findings. Neurol Res 26:778-784, 2004

23. Ogata A, Sonobe M, Kato N, Yamazaki T, Kasuya H, Ikeda $\mathrm{G}$, et al: Carotid artery stenting without post-stenting balloon dilatation. J Neurointervent Surg 6:517-520, 2014

24. Ohki T, Marin ML, Lyon RT, Berdejo GL, Soundararajan $\mathrm{K}$, Ohki M, et al: Ex vivo human carotid artery bifurcation stenting: correlation of lesion characteristics with embolic potential. J Vasc Surg 27:463-471, 1998

25. Oliver TB, Lammie GA, Wright AR, Wardlaw J, Patel SG, Peek R, et al: Atherosclerotic plaque at the carotid bifurcation: CT angiographic appearance with histopathologic correlation. AJNR Am J Neuroradiol 20:897-901, 1999

26. Piñero P, González A, Martínez E, Mayol A, Rafel E, González-Marcos JR, et al: Volume and composition of emboli in neuroprotected stenting of the carotid artery. AJNR Am J Neuroradiol 30:473-478, 2009

27. Qazi U, Obeid TE, Enwerem N, Schneider E, White JR, Freischlag JA, et al: The effect of ballooning following carotid stent deployment on hemodynamic stability. J Vasc Surg 59:756-760, 2014

28. Roubin GS, Iyer S, Halkin A, Vitek J, Brennan C: Realizing the potential of carotid artery stenting: proposed paradigms for patient selection and procedural technique. Circulation 113:2021-2030, 2006

29. Trelles M, Eberhardt KM, Buchholz M, Schindler A, BayerKarpinska A, Dichgans M, et al: CTA for screening of complicated atherosclerotic carotid plaque-American Heart Association type VI lesions as defined by MRI. AJNR Am J Neuroradiol 34:2331-2337, 2013

30. U-King-Im JM, Fox AJ, Aviv RI, Howard P, Yeung R, Moody $\mathrm{AR}$, et al: Characterization of carotid plaque hemorrhage: a CT angiography and MR intraplaque hemorrhage study. Stroke 41:1623-1629, 2010

31. Vitek JJ, Roubin GS, Al-Mubarek N, New G, Iyer SS: Carotid artery stenting: technical considerations. AJNR Am J Neuroradiol 21:1736-1743, 2000

32. Walker LJ, Ismail A, McMeekin W, Lambert D, Mendelow $\mathrm{AD}$, Birchall D: Computed tomography angiography for the evaluation of carotid atherosclerotic plaque: correlation with histopathology of endarterectomy specimens. Stroke 33:977-981, 2002

33. Wittkugel O, Fiehler J, Koch C, Eckert B, Kilic E, Frahm $\mathrm{M}$, et al: Endovascular treatment of internal carotid artery stenosis: effect of primary stent application on debris particle release in human cadaveric specimens. Radiology 229:855860,2003

34. Zhao S, Gu L, Froemming SD: Finite element analysis of the implantation of a self-expanding stent: impact of lesion calcification. J Med Device 6:021001, 2012

\section{Author Contributions}

Conception and design: Pelz, Lownie. Acquisition of data: Pelz, Lownie, Lee. Analysis and interpretation of data: Pelz, Lownie. Drafting the article: Pelz, Lownie. Critically revising the article: Lee, Boulton.

\section{Correspondence}

David M. Pelz, Department of Medical Imaging, University Hospital, London Health Sciences Centre, 339 Windermere Rd., London, ON N6A 5A5, Canada. email: pelz@uwo.ca. 